\title{
Magnified Endoscopic Observations of a Living Whipworm
}

\author{
Kinichi Hotta, Kenichiro Imai and Sayo Ito
}

Key words: whipworm, Trichuris trichiura, colon, colonoscopy, magnified endoscopy, narrow band imaging

(Intern Med 59: 3239-3240, 2020)

(DOI: 10.2169/internalmedicine.5373-20)

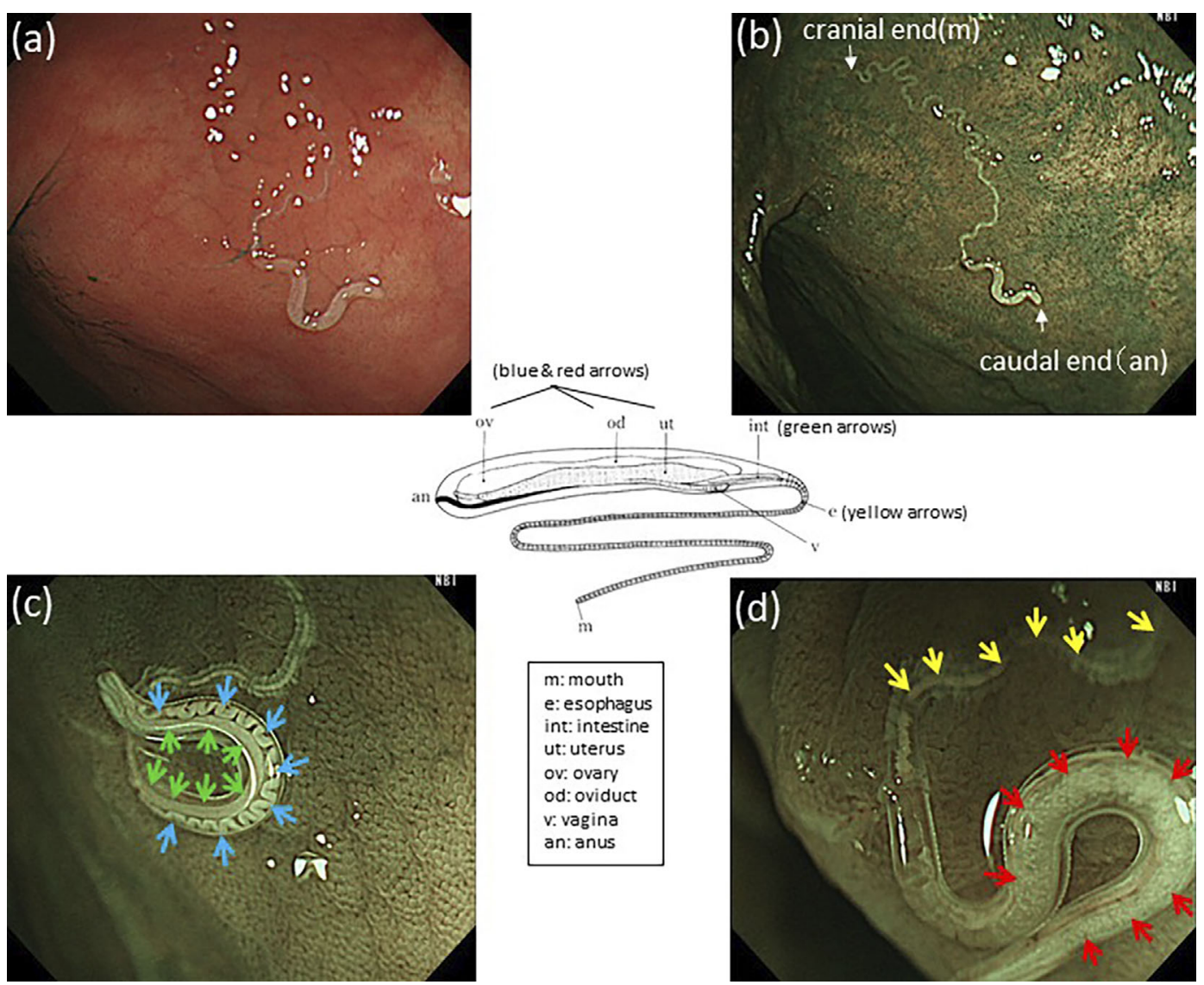

Picture 1.

An asymptomatic 64-year-old man with a colonic polyp was referred to our department. He underwent colonoscopy and a whitish worm was detected in the transverse colon (Picture 1a). Narrow band imaging revealed a whole parasite body (Picture 1b). It could be diagnosed as a whipworm (Trichuris trichiura) due to its specific form (1). Its thin cranial end was invading the mucosa and the opposite caudal end was freely moving. This parasite was confirmed to be a female because of the straight form of its caudal end. The female genitalia (Picture1c: blue arrows) contained many uterine eggs (Picture 1d: red arrows), while the intestine (Picture 1c: green arrows) and esophagus (Picture 1d: yellow arrows) were identified during in vivo magnifying observation. We finally picked up the moving caudal side by biopsy forceps and removed its whole body. A retrieved specimen revealed a worm body with a colonic mucosa (Picture 2: gray arrows). Two sessions of follow-up colonoscopy revealed no further whipworms over a 14-month period without any medication. 


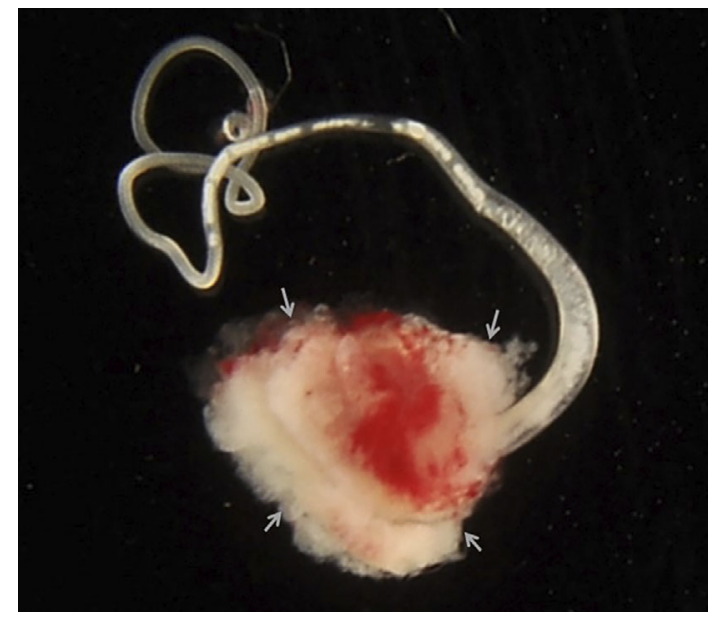

Picture 2.

In Picture 1, a figure of Trichuris trichiura was taken from section 2-7 in ESSENTIALS OF MEDICAL PARASITOLOGY $3^{\text {rd }}$ edit. described by Prof. Isao Tada published by Ishiyaku publishers (2) with the permission of reproduction.

The authors state that they have no Conflict of Interest (COI).

\section{Acknowledgement}

We thank Visiting Prof. Minoru Yamada in Department of Infectious Diseases of Kyoto Prefectural University of Medicine for valuable advice about detailed findings Trichuris trichiura.

\section{References}

1. Taguchi $\mathrm{H}$, Yamamoto $\mathrm{H}$, Miyata $\mathrm{T}$, et al. In vivo diagnosis of whipworm (Trichuris trichiura) with high-definition magnifying colonoscope (with video). Gastrointest Endosc 68: 376-377, 2008.

2. ESSENTIAL PARASITOLOGY. 3rd ed. Tada I, Outomo H, Eds. Trichuris tritiura. Ishiyaku Publishres, Tokyo, 1999: 140-141.

The Internal Medicine is an Open Access journal distributed under the Creative Commons Attribution-NonCommercial-NoDerivatives 4.0 International License. To view the details of this license, please visit (https://creativecommons.org/licenses/ by-nc-nd/4.0/).

(C) 2020 The Japanese Society of Internal Medicine Intern Med 59: 3239-3240, 2020 